\title{
POSTOPERATIVE ANALGESIC EFFICACY OF INTRATHECAL TRAMADOL VERSUS NALBUPHINE ADDED TO BUPIVACAINE IN SPINAL ANAESTHESIA FOR LOWER LIMB ORTHOPAEDIC SURGERY
}

\author{
Devendra Vermaํ, Udita Naithani2 ${ }^{2}$, Dharm Chand Jain ${ }^{3}$, Ajay Singh ${ }^{4}$
}

\section{HOW TO CITE THIS ARTICLE:}

Devendra Verma, Udita Naithani, Dharm Chand Jain, Ajay Singh. "Postoperative analgesic efficacy of intrathecal tramadol versus nalbuphine added to bupivacaine in spinal anaesthesia for lower limb orthopaedic surgery". Journal of Evolution of Medical and Dental Sciences 2013; Vol2, Issue 33, August 19; Page: 6196-6206.

ABSTRACT: BACKGROUND: Effect of adding intrathecal tramadol and nalbuphine to local anaesthetics in spinal anaesthesia is not much studied. STUDY DESIGN: A prospective, randomised double blind placebo controlled study. METHODS: 90 adult patients of ASA grade I-II scheduled for lower limb orthopaedic surgery under spinal anaesthesia were randomised to three groups of 30 each destined to receive $2.5 \mathrm{ml}(12.5 \mathrm{mg})$ hyperbaric bupivacaine $(0.5 \%)$ along with $1 \mathrm{ml}$ of either normal saline (Group C) 50mg tramadol (Group T) or 2mg nalbuphine (Group N), making intrathecal drug volume to $3.5 \mathrm{ml}$ in each group. Sensory-motor block characteristics, postoperative analgesia in terms of VAS score, time to first rescue analgesic (duration of analgesia) and rescue analgesic consumption (tramadol) in 24 hours were compared in three groups. RESULTS: All three groups were comparable regarding onset and extent of sensory and motor block, $(p>0.05)$. However, time to two dermatomal regression and time for complete motor recovery were significantly longer in Group $\mathrm{N}$ than in Group $\mathrm{T}$ than in Group $\mathrm{C},(\mathrm{p}<0.05)$. Duration of analgesia was significantly longer in Group N (378.0 $\pm 35.72 \mathrm{~min} \approx 6.3 \mathrm{hr})$ as compared to Group C $(234.0 \pm 24.10 \mathrm{~min} \approx 3.9)(\mathrm{p}=0.000)$ and Group $\mathrm{T}(260.0 \pm 26.52 \mathrm{~min} \approx 4.3 \mathrm{hr})(\mathrm{p}=0.00)$ while Group $\mathrm{C}$ and Group $\mathrm{T}$ were comparable. CONCLUSION: We conclude that addition of intrathecal nalbuphine $2 \mathrm{mg}$ is effective in enhancing postoperative analgesia as compared to when bupivacaine was used alone or along with tramadol.

KEY WORDS: Postoperative analgesia, intrathecal opioids, nalbuphine, tramadol.

INTRODUCTION: Regional techniques, such as spinal anaesthesia may offer advantages over general anaesthesia including reduced stress response to surgery and analgesia extending into the postoperative period ${ }^{1,2}$. To increase the duration of analgesia produced by local anesthetic, a number of adjuvants has been added through the central neuraxial route 3 . Intrathecal opioid administration has been demonstrated to provide effective postoperative analgesia after a variety of surgical procedures ${ }^{4}$. Opioids work in the intrathecal space by activating opioid- receptors in the dorsal gray matter of spinal cord, which modulates the function of afferent pain fibers ${ }^{2}$. Intrathecal and epidural narcotics seem to modulate pain primarily at the spinal cord rather than in the brain as do intravenous narcotics. Site of action in the spinal cord may provide analgesia with less sedation, confusion and nausea, which are adverse effects associated with intravenous narcotics.

It is now well established that the addition of small dose of intrathecal morphine (0.05-0.5 $\mathrm{mg}$ ) or fentanyl (10-25 mcg) prolongs postoperative analgesia ${ }^{4}$. The most common side effects of intrathecal opioids are nausea, vomiting, pruritus and respiratory depression, the latter being the most feared by clinicians ${ }^{3}$. Side effects are mediated by opioid receptors especially mu receptors ${ }^{5}$. The use of small intrathecal dose reduces the incidence of respiratory depression but the incidence 


\section{ORIGINAL ARTICLE}

of postoperative nausea vomiting and pruritus remain high ${ }^{6}$. Furthermore, morphine and fentanyl come under Narcotics Act, making all time availability a major concern in many hospitals in India. Hence, opioids with fewer adverse effects and easy availability are being in search.

Tramadol, in contrast, is a centrally acting analgesic that has minimal respiratory depressant effects 7,8 , by virtue of its 6000 -fold decreased affinity for mu receptors as compared with morphine 9, 10. It also inhibits serotonin and norepinephrine reuptake in the spinal cord and has no reported neural toxicity ${ }^{11}$. Accordingly, tramadol has the potential to provide effective postoperative analgesia with no risk of respiratory depression after central neuraxial administration ${ }^{12}$.

Nalbuphine, a drug with mixed $\mu$ antagonist and $\mathrm{k}$ agonist properties, is related chemically to oxymorphone and naloxone. It is equal in potency as analgesic to morphine, and one-fourth as potent as nalorphine as an antagonist. Nalbuphine has the potential to maintain or even enhance $\mu$ opioid based analgesia while simultaneously mitigating the $\mu$-opioid side effect ${ }^{5}$.

Various authors have investigated the use of tramodol ${ }^{12,13}$ and nalbuphine,6,14,15 as adjuvant to intrathecal local anaesthetics for prolongation of postoperative analgesia as compared to control with conflicting results. Moreover the data which establish superiority of one agent over another are still sparse ${ }^{16}$.

Hence the present study was undertaken as a randomized double blind placebo controlled trial to assess the effect of intrathecally administered tramadol (50mg) or nalbuphine (2mg) when added to hyperbaric bupivacaine $(12.5 \mathrm{mg}$ ) on the duration of postoperative analgesia (time to first rescue) and rescue analgesic consumption in first 24 hours postoperatively as a primary outcome. Secondary outcome of the study were effect on onset and duration of sensory and motor block, visual analogue scores (VAS) for pain and adverse effects.

MATERIALS AND METHODS: After approval of the institutional ethical committee a prospective randomized double blind, placebo controlled study was conducted in Department of Anaesthesia, $\mathrm{M}$ B Hospital attached to RNT medical college, Udaipur (Raj). After taking informed consent, 90 patients of ASA physical status I-II of either sex, aged between 20-60 yrs, weight 50-90 kg and height $\geq 150 \mathrm{~cm}$ posted for lower limb orthopaedic surgeries under spinal anaesthesia were included in the study. Patients with a history of clinically significant cardiovascular, pulmonary, hepatic, renal, neurologic, psychiatric, or metabolic disease were excluded. Patients who were unable to understand VAS assessment, patients having severe obesity (BMI $>35 \mathrm{~kg} / \mathrm{m}^{2}$ ), coagulation disorder, on anticoagulants, severe spinal deformity, allergy to local anaesthetic, or any contraindication to spinal anaesthesia were also excluded from the study.

Ninety study patients were randomly allocated to three groups of 30 patients in each group by sealed envelope techniques based on intrathecal dose regime. All patients received $12.5 \mathrm{mg}(2.5$ $\mathrm{ml}$ ) of $0.5 \%$ hyperbaric bupivacaine intrathecally along with either $1 \mathrm{ml}$ of normal saline (Group C), or $50 \mathrm{mg}(1 \mathrm{ml})$ preservative free tramadol (Group T) or $2 \mathrm{mg}$ of preservative free nalbuphine (Group N). $1 \mathrm{ml}$ ampoule of nalbuphine $(10 \mathrm{mg} / \mathrm{ml})$ was diluted with $5 \mathrm{ml}$ normal saline and then $1 \mathrm{ml}(2 \mathrm{mg})$ was added to intrathecal dose. Thus total volume of intrathecal dose in all the three groups was 3.5 $\mathrm{ml}$.

To ensure double blindness for the study intrathecal drugs were prepared by the one anesthesiologist, spinal anaesthesia was given by another anesthesiologist and both were not involved further in the study. Postoperative data were recorded by third anesthesiologist, who was 


\section{ORIGINAL ARTICLE}

unaware of group allocation. Patients, surgeon and nursing staff of postoperative ward were also unaware of group allocation.

Anaesthesia technique: The patients were kept fasting overnight and received tablet alprazolam $0.25 \mathrm{mg}$ orally the night before operation.

Before the commencement of anaesthesia, patients were explained about the methods of sensory and motor assessments. Standard monitoring was done throughout the operation. ECG and pulse-oximetry $\left(\mathrm{SpO}_{2}\right)$ were monitored continuously, while non-invasive blood pressure (NIBP) was measured at 5-min intervals.

After putting peripheral intravenous access with 18G IV cannula patients were preloaded with $10 \mathrm{ml} \mathrm{kg}^{-1}$ infusion of Ringer lactate and injection midazolam $1 \mathrm{mg}$ i.v. was given as premedication. Heart rate and arterial pressure were measured and noted as baseline value.

All patients received spinal anaesthesia via midline approach with patients in the sitting position, under full aseptic precautions. $\mathrm{L}_{3}-\mathrm{L}_{4}$ intervertebral space was identified and lumbar puncture was done by using 25G Quincke spinal needle and free flow of CSF was observed before injecting the study solution intrathecally as per group allocation. At the end of injection, time was noted as time of intrathecal injection and taken as zero $\left(\mathrm{t}_{0}\right)$. All time intervals were calculated from this point of time. The patient was placed in supine position to achieve bilateral block. Heart rate (HR), systolic blood pressure (SBP) and diastolic blood pressure (DBP) were monitored intraoperatively. Throughout the procedure the patient received oxygen at $5 \mathrm{~L} / \mathrm{min}$ through ventimask. Fluid and blood were administered as per need.

Sensory and motor block was assessed in the non operating limb every 2 min up to $10 \mathrm{~min}$. The level of sensory block was evaluated by loss of pinprick sensation with 24 gauge hypodermic needle. Onset of sensory block was assessed in the normal limb by assessing the changes in pinprick sensation every 2 min till no sensation (grade 2) was achieved. Grading score for sensory block (Gromley and Hill 1996) was Grade 0 - Normal sensation, Grade 1 - Blunted sensation, Grade 2 - No sensation. Grade-2 was taken as onset of sensory block.

Grading for motor block was done using Modified Bromage score as: 0 - able to flex hips/knee/ankle (no motor block), 1 - able to move knee/unable to raise extended leg (partial motor block), 2- able to flex ankle, unable to flex knee (near complete motor block), 3 - unable to move any part of lower limb (complete motor block)

Surgery was initiated when the level of sensory block was reached to $\mathrm{T}_{10}$ thoracic dermatome level or above and attainment of complete motor block (Bromage-3), otherwise it was considered as failed spinal and alternative technique of anesthesia was chosen and case was excluded from the study.

Hemodynamic parameters like heart rate (HR), systolic blood pressure (SBP), mean arterial pressure (MAP) were recorded after spinal injection every $5 \mathrm{~min}$ for the first $30 \mathrm{~min}$, then every 15 min till the end of surgery. Hypotension was categorized as the fall in SBP of more than $20 \%$ from baseline and treated with incremental dose of IV ephedrine $6 \mathrm{mg}$ and total dose given in each patient was noted. Bradycardia was defined as heart rate $<50 \mathrm{bpm}$ and treated with IV atropine $0.4 \mathrm{mg}$.

Data recording: All time intervals were calculated from the time of end of intrathecal injection $\left(\mathrm{t}_{0}\right)$. Onset of sensory block was defined as time to reach sensory block at T10. Peak sensory level and 


\section{ORIGINAL ARTICLE}

time required to achieve it was also recorded. Onset of motor block was defined as time to reach complete motor block (Bromage score 3). For recovery of block, time to two dermatomal regression (D2 regression) and time to complete motor recovery (return to Bromage score 0) were recorded.

Postoperative analgesia: Postoperative pain was assessed by using Visual analogue score (VAS 010) as VAS $0 \mathrm{~cm}$ - No pain and VAS $10 \mathrm{~cm}$ - Maximal pain.VAS was assessed every 30 minutes for six hours, then every 2 hours up to twelve hours and six hourly up to 24 hours postoperatively and rescue analgesic in form of tramadol $100 \mathrm{mg}$ as slow iv infusion was given whenever VAS was $>3$. Patients were instructed to request pain medication from the nurse if they wanted analgesia and not wait for the next scheduled VAS score assessment. The duration of analgesia was defined from the completion of spinal injection to the time of first rescue analgesic administered. Total rescue analgesic consumption in first $24 \mathrm{~h}$ postoperatively was recorded in terms of number of doses and total dose in mg.

Adverse effect: Sedation was assessed by a categorical scale as used by Mostafa et al (2011) ${ }^{16}$ at the same time intervals when VAS was assessed. Sedation was graded as: 1- awake and alert, 2- awake but drowsy, responding to verbal stimulus, 3- drowsy but arousable, responding to physical stimulus, 4- unarousable, not responding to physical stimulus. Respiratory depression was defined as respiratory rate $<8$ or $\mathrm{SpO}_{2}<94 \%$ on room air and treated with oxygen supplementation or ventilator support as needed. Occurrence of postoperative nausea and vomiting (PONV) was noted and treated with inj. Ondansetron $4 \mathrm{mg}$. Incidence of pruritus was noted and treated with inj. pheniramine maleate $2 \mathrm{ml}$ ( $45 \mathrm{mg}$ iv).

\section{Statistical analysis:}

Basis of sample size: The sample size was calculated by using the Epi Info 6 software. The confidence interval was $95 \%$ and the study had power of $95 \%$. The study was based on a earlier investigation by Alhashemi et al in 2003(12) in which they reported a 60\% occurrence of event (effective postoperative analgesia) in the group receiving nalbuphine versus $10 \%$ occurrence in the group receiving normal saline (control).The minimum sample size required in a ratio of 1:1 for case: control were 24 in each group. Accounting for dropout, we decided to include 30 patients in each group.

Data were entered and analyzed with the help of MS Excel EPI info 6 and SPSS. Qualitative or categorical data were presented as number (proportion) and compared with Chi-square test. Quantitative or continuous variables were presented as mean \pm SD and compared using student ' $t$ ' test. Analysis of variance (ANOVA) was applied as per need as test of significance. A post hoc test was used to assess intergroup differences. $p<0.05$ was considered as statistically significant.

RESULTS: All the three groups were statistically comparable regarding mean age, weight, height, sex, ASA grading, diagnosis and duration of surgery, (Table 1).

There was no significant difference in HR, SBP, DBP and Spo2 during intraoperative period among three groups ( $\mathrm{p}>0.05)$ 


\section{ORIGINAL ARTICLE}

Incidence of intraoperative hypotension was minimal and comparable in three groups [3(10\%) in Group C, 4(13.3\%) in Group T, 5(16.6\%) in Group N, p= 0.749], which was successfully treated with ephedrine (mean dose $6 \mathrm{mg}$ ).

Incidence of intraoperative bradycardia was minimal and comparable in three groups [1(3.3\%) in Group C, 4(13.3\%) in Group T, (10\%) in Group N, p= 0.383], which was successfully treated with atropine (mean dose $0.4 \mathrm{mg}$ )

Sensory and motor block characteristics (table 2): All patients of all the three groups achieved desired sensory level of T10 and Bromage score of 3 to allow start of surgery and had successful spinal anaesthesia, thus no case was excluded from the study due to failure of SAB. All cases completed the study period of $24 \mathrm{~h}$, hence there were no dropouts.

Time to reach T10 sensory level was also statistically comparable in all the three groups (Group $\mathrm{C}=4.47 \pm 0.86 \mathrm{~min}$, Group $\mathrm{T}=4.07 \pm 0.98 \mathrm{~min}$, Group $\mathrm{N}=3.73 \pm 1.25 \mathrm{~min}$ ) ( $\mathrm{p}>0.05$ ) .Time to reach peak sensory level were statistically comparable in all three groups (Group $C=9.20 \pm 1.34 \mathrm{~min}$, Group $\mathrm{T}=9.07 \pm 1.14 \mathrm{~min}$, Group $\mathrm{N}=8.93 \pm 1.46 \mathrm{~min})(\mathrm{p}>0.05)$. Median level of peak sensory level was $\mathrm{T} 6$ in all the three groups. Mean peak sensory level was statistically comparable in all the three groups (Group $\mathrm{C}=\mathrm{T} 6.8 \pm 0.9$, Group $\mathrm{T}=\mathrm{T} 6.5 \pm 0.89$, Group $\mathrm{N}=\mathrm{T} 6.1 \pm 0.53) \quad(\mathrm{p}>0.05)$. Time to two dermatomal $\left(\mathrm{D}_{2}\right)$ regression was significantly longer in Group $\mathrm{N}(123.0 \pm 9.15 \mathrm{~min})$ and Group $\mathrm{T}(115.0 \pm 8.2 \mathrm{~min})$ as compared to Group $\mathrm{C}(109.0 \pm 6.7 \mathrm{~min})(\mathrm{P}=0.00$ and $\mathrm{p}=0.005$ respectively) . Time to D2 regression was significantly longer in Group N as compared to Group $\mathrm{T}(\mathrm{p}=0.00)$ (Group N> Group T> Group C).

Onset of motor block as defined by time to reach Bromage score-3 was statistically comparable in three groups (Group $\mathrm{C}=8.53 \pm 1.27 \mathrm{~min}$, Group $\mathrm{T}=8.50 \pm 1.57 \mathrm{~min}$, Group N=7.87 \pm 1.47 min) ( $>>0.05)$. Duration of motor block as defined by return of Bromage score to 0 was significantly longer in group $\mathrm{N}(150 \pm 10.4 \mathrm{~min})$ and Group $\mathrm{T}(137 \pm 8.5 \mathrm{~min})$ as compared to Group C $(129 \pm 7.4 \mathrm{~min})$, $(\mathrm{p}=0.00$ and $\mathrm{p}=0.00$ respectively ). Duration of motor block was significantly longer in Group $\mathrm{N}$ as compared to Group T ( $\mathrm{p}=0.00)$. Thus duration of motor block was Group N > Group T> Group C.

Post-operative analgesia (table-3): Mean VAS score remained less than 4 throughout the study period showing adequate postoperative analgesia in all three groups. Overall value of mean VAS score was significantly more in control group $(1.86 \pm 0.12)$ as compared to group $\mathrm{T}(1.68 \pm 0.14)$ and group $\mathrm{N}(1.33 \pm 0.13)(\mathrm{p}=0.00)$. When group $\mathrm{N}$ and group $\mathrm{T}$ were compared, VAS was significantly less in group $\mathrm{N}$ than to group $\mathrm{T}(\mathrm{p}=0.00)$, thus order of VAS was (Group $\mathrm{N}<$ Group $\mathrm{T}<$ Group $\mathrm{C}$ ).

Requirement of first dose of rescue analgesic was significantly delayed in Group $\mathrm{N}$ $(378.0 \pm 35.72 \mathrm{~min} \approx 6.3 \mathrm{hr})$ as compared to Group C $(234.0 \pm 24.10 \mathrm{~min} \approx 3.9),(\mathrm{p}=0.000)$ and Group $\mathrm{T}$ $(260.0 \pm 26.52 \mathrm{~min} \approx 4.3 \mathrm{hr}),(\mathrm{p}=0.00)$ but there was no significant difference between group $\mathrm{C}$ and group $\mathrm{T}(\mathrm{p}=0.065)$ thus duration of postoperative analgesia was Group $\mathrm{N}>$ Group $\mathrm{T} \approx$ Group C, (fig1). Prolongation of postoperative analgesia occurred by approximately $62 \%$ with addition of nalbuphine and $11 \%$ with addition of tramadol as compared to when bupivacaine was used alone.

Requirement of total rescue analgesic in term of total number of doses was significantly less in Group N(48) as compared to Group C(77), ( $\mathrm{p}=0.00)$ and Group T(70), (p=0.00). However Group C and Group $\mathrm{T}$ were statistically comparable ( $\mathrm{p}=0.068)$, (fig-2). Rescue analgesic consumption was reduced by approximately $38 \%$ by addition of nalbuphine and $9 \%$ by addition of tramadol as 


\section{ORIGINAL ARTICLE}

compared to when bupivacaine was used alone. Thus rescue analgesic consumption was Group $\mathrm{N}<$ Group T $\approx$ Group C.

Postoperative adverse effects: Incidence of hypotension [Group C-2(6.6\%), Group T-3(10\%), Group N-4(13.3\%), (p=0.606) and bradycardia (Group C-1(3.3\%), Group T-1(3.3\%), Group N$2(6.6 \%)(p=0.680)]$ during first 24 hours period was minimal and statistically comparable in all the three groups and their occurrence was attributed to surgical procedure and tourniquet deflation. Incidence of nausea [Group C-2(6.6\%), Group T-3(10\%), Group N-3(10\%) ( $\mathrm{p}=0.829)$, vomiting (Group C-1(3.3\%), Group T-2(6.6\%), Group N-1(3.3\%) (p=0.680)]. Respiratory depression as shown by $\mathrm{SpO} 2<94 \%$ on room air occurred in $1(3.3 \%)$ patient of group $\mathrm{N}$ at 2 hours postoperatively which was successfully treated by supplementation of oxygen by ventimask $5 \mathrm{l} / \mathrm{m}$. None of the patients in Group $\mathrm{C}$ and Group $\mathrm{T}$ had respiratory depression. Thus incidence of respiratory depression in the study was minimal and comparable $(\mathrm{p}>0.05)$. Occurrence of pruritus [Group C 0\%, Group T$1(3.3 \%)$, Group N-2(6.6\%)] was also minimal and statistically comparable ( $p>0.05)$ in three groups, which was successfully treated with Inj pheniramine IV.

Mean sedation score was $1.033 \pm 0.50$ in Group C and Group T and $1.133 \pm 0.50$ in Group N which was comparable $(\mathrm{p}=0.606)$. It signifies negligible sedation in three groups.

DISCUSSION: Use of intrathecal opioids as adjuncts to intrathecal local anaesthetics has a definite place in present regional anaesthesia practice. Intrathecal opioids selectively decrease nociceptive input from A delta and C fibres without affecting dorsal root axons or somatosensory evoked potentials 4 . Various opioids like morphine and fentanyl which are pure mu agonists are being used along with bupivacaine to prolong its effect, to improve the quality of analgesia and minimizing the requirement of postoperative analgesics. The side effects of mu opioid analgesics are pruritus, nausea, emesis, respiratory depression, constipation and urinary retention ${ }^{3}$. Therefore, alternative opioids like nalbuphine and tramadol are being investigated for intrathecal use.

This study is conducted to test the hypothesis whether addition of tramadol $50 \mathrm{mg}$ or nalbuphine $2 \mathrm{mg}$ to intrathecal $12.5 \mathrm{mg}$ of hyperbaric bupivacaine could improve postoperative analgesia following lower limb orthopaedic surgery.

The study showed that intrathecal addition of tramadol or nalbuphine to hyperbaric bupivacaine potentiated the onset and extent of sensorimotor block of spinal anaesthesia but could not make a statistical difference. Previous studies have also shown that onset time and peak sensory level was not significantly affected after addition of intrathecal tramadol ${ }^{13,16}$ or nalbuphine ${ }^{14-16}$.

In this study duration of sensory block (time to two dermatomal regression) was significantly increased by addition of nalbuphine and tramadol both, however previous studies have observed that time to two dermatomal regression was significantly prolonged with nalbuphine ${ }^{14,15}$ not by tramadol ${ }^{13}$.

In present study, duration of motor block was significantly increased by tramadol and nalbuphine but other authors found no prolongation of motor block, ${ }^{13-16 .}$

Intrathecal local anesthetics work by inhibiting voltage gated sodium channels in the spinal cord, which interferes with afferent and efferent sensory and motor impulses ${ }^{2}$. Opioids work in the intrathecal space by activating opioids receptors in the dorsal gray matter of spinal cord, which 


\section{ORIGINAL ARTICLE}

modulates the function of afferent pain fibers ${ }^{2}$. Opioids were found synergistic with bupivacaine in reducing pain without measurably increasing sympathetic or motor blockade in dog modals ${ }^{17}$.

It has observed that addition of tramadol or nalbuphine allowed a significant reduction in pain score as documented by others ${ }^{12,14-16 .}$

Present study showed that postoperative analgesia was significantly improved by addition of nalbuphine, it allowed $62 \%$ prolongation in duration of analgesia and 38\% reduction in analgesic consumption in 24 hours as compared to when bupivacaine was used alone. Nalbuphine is an opioid structurally related to oxy-morphone. It is highly lipid soluble opioid with an agonist action at the $\mathrm{k}$ opioid receptor and antagonist activity at the $\mu$ opioid receptor. Nalbuphine and other k agonist have provided reasonably potent analgesia in certain models of visceral nociception ${ }^{14}$. That's why when used intrathecally as an adjuvant to spinal anaesthesia they were found to improve the quality of intraoperative and postoperative analgesia with fewer side effects. Nalbuphine had been used intrathecal in dose of $0.2 \mathrm{mg}^{6,14}, 0.4 \mathrm{mg}^{14}, 0.8 \mathrm{mg}^{6,14}, 1.6 \mathrm{mg}^{6}, 2 \mathrm{mg}^{15,16}$ and $4 \mathrm{mg}^{15}$ by various authors and the dose $0.8 \mathrm{mg}$ or more were found effective in enhancing postoperative analgesia ${ }^{6,15}$.

However we observed that addition of tramadol prolonged the duration by $11 \%$ and allowed a reduction of rescue analgesic consumption by only $9 \%$ which was comparable to control group. Tramadol had been used intrathecally in dose of $10 \mathrm{mg}^{18}, 20 \mathrm{mg}^{19}, 25 \mathrm{mg}^{12,13}$, and $50 \mathrm{mg}^{16}$ and some reported prolongation of analgesia ${ }^{13,19}$ and others found no significant difference ${ }^{14}$.

Alhashemi et al in $2003^{12}$ used $25 \mathrm{mg}$ tramadol along with $15 \mathrm{mg}$ bupivacaine for TURP and reported no significant improvement in postoperative analgesia. Failure of intrathecal tramadol in providing effective postoperative analgesia was attributed to number of factors. Firstly the tramadol dose used in this study could have been too small for a clinically relevant analgesic effect to be detected. Secondly, tramadol has decreased affinity for $\mu$ receptor, which is the site of action for spinally administered opioids. Thirdly, it is possible that the lipophilic properties of tramadol resulted in rapid diffusion of the drug out of subarachnoid space.

No significant opioid related adverse effects were observed in our study. Previous studies also documented intrathecal tramadol and nalbuphine as safer adjuvants ${ }^{12,14,16 .}$

CONCLUSION: We conclude that addition of nalbuphine $(2 \mathrm{mg})$ to intrathecal hyperbaric bupivacaine $(12.5 \mathrm{mg}$ ) for spinal anaesthesia is effective in prolonging the duration of sensorimotor block and enhancing the postoperative analgesia following lower limb orthopaedic surgery, with negligible adverse effects. It produced a significant prolongation (62\%) in duration of post operative analgesia and contributed to a significant reduction in rescue analgesic consumption (38\%) in first 24 hours postoperatively. However, addition of intrathecal tramadol (50 mg) could not make a significant difference in postoperative analgesia as compared to when bupivacaine was used alone. Hence, present study establishes the efficacy of nalbuphine (2mg) as an intrathecal adjuvant to bupivacaine for enhancing the postoperative analgesia. 


\section{OBSERVATIONS AND RESULTS}

Table 1: Demographic characteristics

\begin{tabular}{|c|c|c|c|c|c|}
\hline \multicolumn{2}{|c|}{ Variables } & $\begin{array}{c}\text { Group C } \\
(n=30)\end{array}$ & $\begin{array}{c}\text { Group T } \\
(n=30)\end{array}$ & $\begin{array}{c}\text { Group N } \\
(n=30)\end{array}$ & p Value \\
\hline \multicolumn{2}{|c|}{ Age (yr) } & $40.13 \pm 11.7$ & $37.07 \pm 13.8$ & $39.03 \pm 14.6$ & 0.581 \\
\hline \multirow{2}{*}{ Sex } & Male & $24(80.0 \%)$ & $25(83.3 \%)$ & $22(73.3 \%)$ & \multirow{2}{*}{0.627} \\
\hline & Female & $6(20.0 \%)$ & $5(16.7 \%)$ & $8(26.7 \%)$ & \\
\hline \multirow{2}{*}{ ASA Grade } & Grade 1 & $25(80.3 \%)$ & $26(83.3 \%)$ & $24(80.0 \%)$ & \multirow{2}{*}{0.787} \\
\hline & Grade 2 & $5(16.7 \%)$ & $4(13.3 \%)$ & $6(20.0 \%)$ & \\
\hline \multicolumn{2}{|c|}{ Weight(kg) } & $61.47 \pm 4.90$ & $63.57 \pm 4.85$ & $62.07 \pm 5.72$ & 0.277 \\
\hline \multicolumn{2}{|c|}{ Height $(\mathrm{cm})$} & $160.20 \pm 4.90$ & $162.20 \pm 5.86$ & $160.33 \pm 5.90$ & 0.490 \\
\hline \multicolumn{2}{|c|}{$\begin{array}{c}\text { Duration of } \\
\text { surgery(min) }\end{array}$} & $74.33 \pm 11.42$ & $72.33 \pm 14.60$ & $76.00 \pm 14.34$ & 0.610 \\
\hline
\end{tabular}

Data are mean \pm SD, or $n(\%)$ as appropriate.

Table 2: Sensory and motor block characteristics after subarachnoid block

\begin{tabular}{|c|c|c|c|c|c|c|c|}
\hline & \multirow{2}{*}{$\begin{array}{c}\text { Group C } \\
(n=30)\end{array}$} & \multirow{2}{*}{$\begin{array}{c}\text { Group T } \\
(n=30)\end{array}$} & \multirow{2}{*}{$\begin{array}{c}\text { Group N } \\
(n=30)\end{array}$} & \multicolumn{3}{|c|}{ P Value } \\
\hline & & & & & $\mathrm{C} / \mathrm{T}$ & $\mathbf{C} / \mathbf{N}$ & $\mathbf{N} / \mathbf{T}$ \\
\hline \multicolumn{2}{|l|}{$\begin{array}{l}\text { Time to reach } \mathrm{T}_{10} \\
\text { sensory level (min) }\end{array}$} & $4.47 \pm 0.86$ & $4.07 \pm 0.98$ & $3.93 \pm 1.25$ & 0.142 & 0.08 & 0.220 \\
\hline \multicolumn{2}{|l|}{$\begin{array}{l}\text { Time to reach max } \\
\text { sensory level (min) }\end{array}$} & $9.20 \pm 1.34$ & $9.07 \pm 1.14$ & $8.93 \pm 1.46$ & 0.697 & 0.697 & 0.438 \\
\hline \multirow{2}{*}{$\begin{array}{l}\text { Patient distribution } \\
\text { according to peak sensory } \\
\text { level }\end{array}$} & $\mathrm{T}_{8}$ & $18(60 \%)$ & $22(73.3 \%)$ & $28(93.3 \%)$ & & & \\
\hline & $\mathrm{T}_{6}$ & $12(40 \%)$ & $8(26.6 \%)$ & $2(6.66 \%)$ & & & \\
\hline \multicolumn{2}{|l|}{$\begin{array}{l}\text { Mean peak sensory } \\
\text { level(Range) }\end{array}$} & T6.8 \pm 0.99 & Т6.53 \pm 0.89 & T6.13 \pm 0.53 & & & \\
\hline \multicolumn{2}{|l|}{ Median peak sensory level } & $\begin{array}{c}\mathrm{T}_{6} \\
\left(\mathrm{~T}_{6}-\mathrm{T}_{8}\right)\end{array}$ & $\begin{array}{c}\mathrm{T}_{6} \\
\left(\mathrm{~T}_{6}-\mathrm{T}_{8}\right)\end{array}$ & $\begin{array}{c}\mathrm{T}_{6} \\
\left(\mathrm{~T}_{6}-\mathrm{T}_{8}\right)\end{array}$ & & & \\
\hline \multicolumn{2}{|l|}{ Time to D2 regression(min) } & $109.00 \pm 6.74$ & $115.00 \pm 8.20$ & $123.00 \pm 9.15$ & 0.005 & 0.00 & 0.00 \\
\hline \multicolumn{2}{|l|}{$\begin{array}{l}\text { Time to reach } \\
\text { complete motor block } \\
\text { (Bromage-3) (min) }\end{array}$} & $8.53 \pm 1.27$ & $8.30 \pm 1.57$ & $7.87 \pm 1.47$ & 0.078 & 1.00 & 0.078 \\
\hline \multicolumn{2}{|l|}{$\begin{array}{l}\text { Duration of motor blockade } \\
\text { (Time to reach Bromage } 0 \text { ) } \\
\text { (min) }\end{array}$} & $129.0 \pm 7.47$ & $137.80 \pm 8.59$ & $150.0 \pm 10.42$ & 0.00 & 0.00 & 0.00 \\
\hline
\end{tabular}

Data are mean $\pm \mathrm{SD}$, or $\mathrm{n}(\%)$ as appropriate. 


\section{ORIGINAL ARTICLE}

Table 3: Requirement of Post Operative rescue Analgesic dose in 24 Hours

\begin{tabular}{|c|c|c|c|c|c|c|c|}
\hline & \multirow{2}{*}{$\begin{array}{l}\text { Group C } \\
(n=30)\end{array}$} & \multirow{2}{*}{$\begin{array}{l}\text { Group T } \\
(n=30)\end{array}$} & \multirow{2}{*}{$\begin{array}{c}\text { Group N } \\
(n=30)\end{array}$} & \multicolumn{3}{|c|}{ P Value } \\
\hline & & & & & $\mathrm{C} / \mathrm{T}$ & $\mathrm{C} / \mathrm{N}$ & $\mathbf{N} / \mathbf{T}$ \\
\hline \multicolumn{2}{|c|}{$\begin{array}{l}\text { No of patient requiring } \\
\text { rescue analgesia in } 24 \mathrm{hr}\end{array}$} & 30 & 30 & 30 & & & \\
\hline \multicolumn{2}{|c|}{ Time to first rescue analgesia } & $\begin{array}{c}234.0 \pm 24.10 \mathrm{~min} \\
(3.9 \mathrm{hr})\end{array}$ & $\begin{array}{l}260.0 \pm 26.52 \mathrm{~min} \\
(4.3 \mathrm{hr})\end{array}$ & $\begin{array}{l}378.0 \pm 35.72 \mathrm{~min} \\
(6.3 \mathrm{hr})\end{array}$ & 0.065 & 0.00 & 0.00 \\
\hline \multicolumn{2}{|c|}{$\begin{array}{l}\text { Percentage prolongation in time } \\
\text { to first rescue analgesia }\end{array}$} & - & $\begin{array}{l}11.11 \% \\
\approx 11 \% \uparrow\end{array}$ & $\begin{array}{c}61.53 \% * \\
62 \% \uparrow\end{array}$ & & & \\
\hline \multirow{3}{*}{$\begin{array}{l}\text { No of patient } \\
\text { requiring }\end{array}$} & 1 dose & $0 \%$ & $0 \%$ & $12(40 \%)$ & & & \\
\hline & 2 doses & $13(43.3 \%)$ & $20(66.6 \%)$ & $18(60 \%)$ & & & \\
\hline & 3 doses & $17(56.6 \%)$ & $10(33.3 \%)$ & 0 & & & \\
\hline \multicolumn{2}{|c|}{$\begin{array}{l}\text { Total no. of doses of rescue } \\
\text { analgesic }\end{array}$} & 77 & 70 & 48 & 0.068 & 0.00 & 0.00 \\
\hline \multicolumn{2}{|c|}{$\begin{array}{l}\text { Percentage reduction in total } \\
\text { rescue analgesia }\end{array}$} & - & $\begin{array}{c}9.09 \% \\
9 \% \downarrow\end{array}$ & $\begin{array}{c}37.66 \% * \\
38 \% \downarrow\end{array}$ & & & \\
\hline \multicolumn{2}{|c|}{$\begin{array}{l}\text { Total dose of rescue analgesic in } \\
(\mathrm{mg})\end{array}$} & 7700 & 7000 & 4800 & & & \\
\hline \multicolumn{2}{|c|}{ Mean no of dose for each patient } & $2.57 \pm 0.50$ & $2.33 \pm 0.47$ & $1.60 \pm 0.49$ & 0.071 & 0.00 & 0.00 \\
\hline \multicolumn{2}{|c|}{$\begin{array}{l}\text { Mean dose in mg for each } \\
\text { patient }\end{array}$} & $256.56 \pm 50.40$ & $233.33 \pm 47.94$ & $156.67 \pm 50.40$ & 0.072 & 0.00 & 0.00 \\
\hline
\end{tabular}

Data are mean $\pm \mathrm{SD}$, or $\mathrm{n}(\%)$ as appropriate.

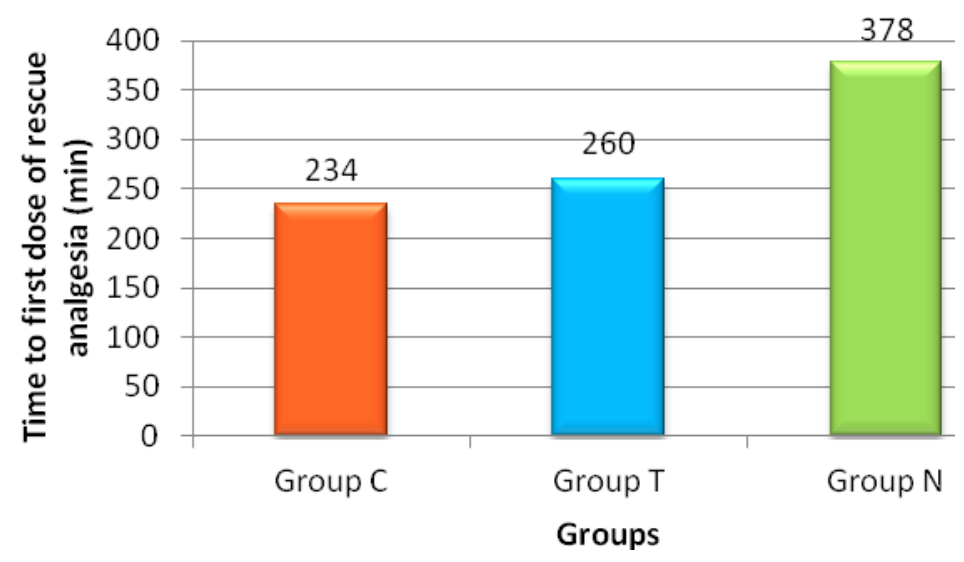

Fig.1: Comparison of mean time to first dose of rescue analgesic (min) in three groups 


\section{ORIGINAL ARTICLE}

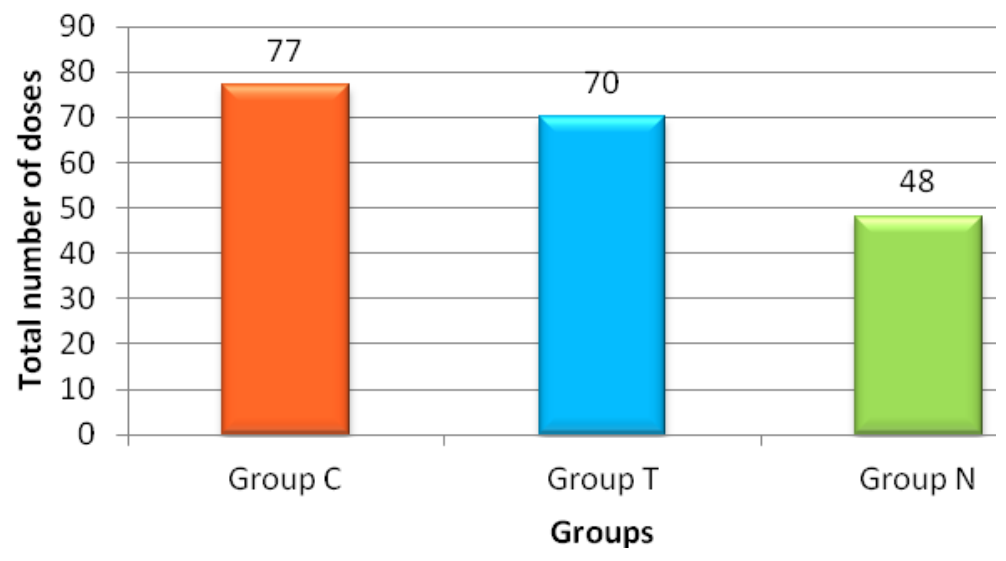

Fig.2: Comparison of total number of doses of rescue analgesic in three groups

\section{REFERENCES:}

1. Andres J, Valia JC, Gill A, Bolinches R. Predictor of patient satisfaction with regional anesthesia. Reg Anesth 1995;20:198-505

2. Roussel JR, Heindel L. Effect of intrathecal fentanyl on duration of bupivacaine spinal blockade for outpatient knee arthroscopy. AANA J 1999; 67(4):337-43

3. Gandhi K, Viscusi E. Multimodal pain management techniques in hip and knee arthoplasty. Journal of NYSORA 2009;13:1-8

4. Hindle A. Intrathecal opioids in the management of acute postoperative pain. Continuing Education in Anaesthesia, Critical Care and Pain. Br J Anaesth 2008; 8(3):81-85

5. Gunion MW, Marchionne AM, Anderson TM. Use of the mixed agonist-antagonist nalbuphine in opioid based analgesia. Acute Pain 2004; 6:29-39

6. Culebras X, Gaggero G, Zatloukal J, Kern C, Marti RA. Advantages of intrathecal nalbuphine, compared with intrathecal morphine, after cesarean delivery. Anesth Analg 2000; 91:601-5

7. Vickers MD, O'Flaherty D, Szekely SM, Read M, Yoshizumi J. Tramadol: pain relief by an opioid without depression of respiration. Anaesthesia 1992; 47: 291-6

8. Tarkkila P, Tuominen M, Lindgren L. Comparison of respiratory effects of tramadol and pethidine. Eur J Anaesthesiol 1998; 15: 64-8

9. Raffa RB, Friderichs E, Reimann W, Shank RP, Codd EE, Vaught JL. Opioid and nonopioid components independently contribute to the mechanism of action of tramadol, an 'atypical' opioid analgesic. J Pharmacol Exp Ther 1992; 260: 275-85

10. Scott LJ, Perry CM. Tramadol: a review of its use in perioperative pain. Drugs 2000; 60: 13976

11. Tsai YC, Chang PJ, Jou IM. Direct tramadol application on sciatic nerve inhibits spinal somatosensory evoked potentials in rats. Anesth Analg 2001; 92: 1547-51

12. Alhashemi JA, Kaki AM. Effect of intrathecal tramadol administration on postoperative pain after transurethral resection of prostate. Br J Anaesth 2003; 91(4):536-40

13. Mankeshwar HJ, Ganesh S. Pre-emptive analgesia with intrathecal tramadol for postoperative analgesia. J Clin Epidemil1997; 50(1):7S-7S(1) 
14. Mukherjee A, Pal A, Agrawal J, Mehrotra A, Dawar N. Intrathecal nalbuphine as an adjuvant to subarachnoid block. Anesthesia Essays and Researches 2011; 5(2):171-175

15. Tiwari AK, Tomar GS, Agrawal J. Intrathecal Bupivacaine in comparison with a combination of nalbuphine and bupivacaine for subarachnoid block. Am J Ther 2011; 8

16. Mostafa MG, Mostafa MF, Farrag WSH. Which has greater effect, intrathecal nalbuphine or intrathecal tramadol. J Am Sci 2011; 7(7):480-84

17. Tejwani GA, Rattan AK, McDonald JS. Role of spinal opioid receptor in the antinociceptive interaction between intrathecal morphine and bupivacaine. Anesth Analg 1992; 74:726-734

18. Jung JI, Kang PS. The effect of intrathecal tramadol and clonidine on saddle block with heavy bupivacaine. Korean J Anesthesiol 1999; 37(2):227-232

19. Chakraborty S, Chakraborty J, Bhattacharya D. Intrathecal tramadol added to bupivacaine as spinal anesthetic increase analgesic effect of the spinal blockade after major gynecological surgeries. Indian J Anaesth 2008; 40(4):180-182.

\section{AUTHORS:}

1. Devendra Verma

2. Udita Naithani

3. Dharm Chand Jain

4. Ajay Singh

\section{PARTICULARS OF CONTRIBUTORS:}

1. Associate Professor, Department of Anaesthesia, RNT Medical College attached to MB hospital, Udaipur (Rajasthan), India.

2. Associate Professor, Department of Anaesthesia, RNT Medical College attached to MB hospital, Udaipur (Rajasthan), India.

3. Senior Resident, Department of Anaesthesia, RNT Medical College attached to MB hospital, Udaipur (Rajasthan), India.
4. Senior Resident, Department of Anaesthesia, RNT Medical College attached to MB hospital, Udaipur (Rajasthan), India.

\section{NAME ADDRESS EMAIL ID OF THE CORRESPONDING AUTHOR:}

Dr. Dharm Chand Jain, 131, M Road, Bhupalpura, Udaipur (Rajasthan),

India - 313001.

Email-drdharmbkn@rediffmail.com

Date of Submission: 30/07/2013.

Date of Peer Review: 31/07/2013.

Date of Acceptance: 10/08/2013.

Date of Publishing: 14/08/2013 